\title{
O ARGUMENTO DO CONHECIMENTO: UMA NOVA ESTRATÉGIA FISICISTA
}

\section{Roberto Horácio De Sá Pereira ${ }^{1}$}

\begin{abstract}
RESUMO
Neste artigo, apresento e defendo uma versão alternativa à chamada estratégia dos conceitos fenomenais em defesa do materialismo tipo $\mathrm{B}$ no clássico argumento do conhecimento de Jackson. Endossando a crítica de Ball e Tye à estratégia dos conceitos fenomenais, argumento em favor das seguintes teses. Primeira tese: o conteúdo recém-adquirido por Mary é de natureza nãoconceitual à luz de todos critérios disponíveis. Segunda tese: aquisição por Mary de tal conteúdo é justamente o que os permite explicar, ao menos em parte, tanto o seu progresso epistêmico (uma vez liberta do seu confinamento) quanto o incremento da sua expertise relativa ao seu antigo conceito VERMELHO FENOMENAL. Entretanto, embora a aquisição de tal conteúdo não-conceitual seja indispensável, ele são é suficiente para a explicação do progresso epistêmico realizado Mary. Terceira tese, assumindo que conceitos seja arquivos mentais, após a realização das experiências visuais de vermelho pela primeira vez, tal conteúdo não-conceitual recém-adquirido passa por um processo de "digitalização" para, assim, poder ser armazenado no arquivo mental VERMELHO FENOMENAL. Quarta e última tese: é com base nesse conceito de VERMELHO FENOMENAL, agora enriquecido fenomenalmente pelos recém-adquiridos conteúdos não-conceituais, que Mary se torna capaz de identificar o caráter fenomenal da sua nova experiência visual da cor vermelha mediante introspecção da sua experiência visual de vermelho.
\end{abstract}

Palavras-chave: Argumento do Conhecimento. Estratégia dos Conceitos Fenomenais. Conteúdos não-conceituais.

\begin{abstract}
This article presents an alternative defense of type B materialism in Jackson's knowledge Argument. To start with, I argue that on her release, Mary newly acquired content is essentially non-conceptual in the light of all available criteria. Mary's acquisition of such content is precisely what allows us to explain both her epistemic progress and the increase of her expertise regarding her old concept PHENOMENAL RED. Yet, while the acquisition of such non-conceptual content is indispensable, it is still insufficient to explain Mary's epistemic progress. Conceptual contents are required. Now, assuming that concepts are mental files, Mary's newly acquired non-conceptu-

\footnotetext{
${ }^{1}$ Professor Titular de Filosofia pela UFRJ. E-mail: Robertohsp@gmail.com.
} 
al content of RED must be "digitalized" in order to be stored in the correspondent mental file PHENOMENAL RED. It is based on this concept, now phenomenally enriched by the newly acquired non-conceptual contents, that Mary becomes able to pick out the phenomenal character of her new visual experience of the color introspectively.

Keywords: Knowledge Argument. Phenomenal Concept Strategy. Nonconceptual Contents.

\section{Introdução}

Imagino que todos conheçam a história de Mary. Trata-se de uma cientista excepcional que possui conhecimento exaustivo sobre todos os fatos físicos relativos a tantos a cores quanto à visão de cores, mas que está confinada em quarto preto e branco desde o seu nascimento. Um belo dia ela é liberta e contempla a cor vermelha de um tomate maduro e, pela primeira vez, aprende o que é, em suma, se realizar a experiência visual de vermelho. Segundo Jackson, a suposição inicial de que Mary já conhecia de forma exaustivas todos os fatos físicos sobre cores e visão de cores coloca o fisicista diante de um grande problema. Se Mary já conhecia tudo acerca da física das cores e da visão de cores e, ademais, se ela aprende algo novo (ao perceber o vermelho pela primeira vez), a conclusão que se impõe é contrária ao fisicismo: Mary aprende um fato sobre a sua nova experiência de cores que não pode ser físico (cf. JACKSON, 1982, p. 130).

A reação fisicista mais popular ao argumento do conhecimento de Jackson é a suposição de que, uma vez liberta, Mary adquire novos conceitos, conceitos ditos fenomenais, mas que versam sobre a mesma propriedade (cor vermelha) ou fato físico que ela já conhecia por meio do antigo conceito físico VERMELHO que ela possuía em seu confinamento. Seguindo Stoljar, denominaremos essa reação fisicista ao argumento do conhecimento anti-fisicista de estratégia de conceito fenomenal (doravante ECF) (Cf. STOLJAR, 2005).

Este artigo apresenta e defende uma nova defensa do fisicismo, baseado, contudo, versão alternativa (ou se quiserem aprimorada) da ECF. Nele retomo a crítica de Tye e Ball à EFC segundo a qual não existem conceitos fenomenais no sentido especial exigido pela EFC, ou seja, conceitos que só poderiam ser adquiridos mediante a realização da experiência rele- 
vante, no caso em tela, da cor vermelha. No entanto, parece-me inegável que, quando liberta, Mary adquire uma nova representação visual da cor vermelha, um conteúdo representacional que ela só poderia adquirir mediante a realização da sua nova experiência de vermelho. A questão é: que conteúdo seria esse?

Argumento em favor das seguintes teses (todas originais). Primeira tese: o conteúdo recém-adquirido por Mary é de natureza essencialmente não-conceitual à luz de todos critérios disponíveis. Segunda tese: a aquisição por Mary de tal conteúdo não-conceitual é justamente o que os permite explicar, ao menos em parte, tanto o seu progresso epistêmico (uma vez liberta do seu confinamento) quanto o incremento da sua expertise relativa ao seu antigo conceito VERMELHO FENOMENAL. Entretanto, embora a aquisição de tal conteúdo não-conceitual seja indispensável, ele não é suficiente para a explicação do progresso epistêmico realizado Mary. Terceira tese, assumindo que conceitos sejam arquivos mentais, após a realização das experiências visuais de vermelho pela primeira vez, tal conteúdo não-conceitual recém-adquirido passa por um processo de "digitalização" para, assim, poder ser armazenado no arquivo mental VERMELHO FENOMENAL. Quarta e última tese: é com base nesse conceito de VERMELHO FENOMENAL, agora enriquecido fenomenalmente pelos recém-adquiridos conteúdos não-conceituais, que Mary se torna capaz de identificar o caráter fenomenal da sua nova experiência visual da cor vermelha mediante introspecção da sua experiência visual de vermelho.

O restante deste artigo está estruturado da seguinte forma. Na próxima seção, apresento a ECF e retomo as principais críticas de Tye and Ball. Essa seção se impõe como necessária uma vez que as quatro teses a serem defendidas nesse trabalho constituem uma reelaboração da ECF partindo da crítica dos mencionados autores. Na seção seguinte, apresento e defendo as duas primeira teses: (i) o que Mary carece, quando confinada em seu quarto preto e branco, é de uma representação não-conceitual da cor vermelha e do vermelho fenomenal de uma experiência da cor vermelha e não de um suposto conceito fenomenal; (ii) a aquisição de tal conteúdo não-conceitual é o que explica, ao menos em parte, tanto o progresso epistêmico de Mary, quanto o aumento da sua expertise face ao seu antigo conceito VERMELHO 
FENOMENAL. A última seção está consagrada a mostrar que o progresso epistêmico de Mary depende adicionalmente do armazenamento de tal conteúdo não-conceitual em arquivos mentais, no caso em tela do arquivo mental VERMELHO FENOMENAL. A quarta e última tese constitui o corolário da seção: é com base nesse conceito de VERMELHO FENOMENAL, devidamente enriquecido fenomenalmente pelo novo conteúdo não-conceitual, que Mary se torna capaz de identificar o caráter fenomenal da sua experiência visual da cor vermelha mediante introspecção da sua nova experiência visual do vermelho de um tomate maduro.

\section{A ECF e o seu fracasso}

A maneira mais simples reconstruir o argumento do conhecimento de modo a refletir mais fidedignamente o experimento mental de Jackson e facilitar a compreensão das críticas recentes à ECF foi sugerida por Tye (2009, pp. 123-4):

1. Mary, confinada em seu quarto em preto e branco, sabe tudo acerca da física de cores e da visão de cores.

2. Quando liberta, Mary aprende algo de novo, consequentemente,

3. Mary descobre algo cuja natureza não é física, consequentemente,

4. O fisicismo é falso.

A estrutura geral da ECF pode ser brevemente representada da seguinte maneira. Conceitos fenomenais teriam uma natureza especial. Não seriam apenas conceitos comuns usados introspectivamente para identificar o caráter fenomenal da experiência mediante introspeção. Eles antes seriam conceitos especiais no sentido preciso de que só poderíamos adquiri-los quando realizássemos a experiência em questão e atendêssemos ao caráter fenomenal dessa mesma experiência mediante introspecção. Assim, quando contemplasse a cor vermelha de um tomate maduro pela primeira vez e, atendesse ao vermelho fenomenal da sua nova experiência, Mary formaria um novo conceito VERMELHO FENOMENAL. Seria esse conceito que the permitiria identificar o vermelho fenomenal de sua nova experiência medi- 
ante introspecção e, portanto, vir a saber o que é, e suma, se realizar a experiência visual de vermelho.

À ECF caberia levar a cabo duas tarefas (aparentemente contraditórias). Em primeiro lugar, a ECF deveria tornar compreensível a ideia de uma lacuna explicativa entre propriedades físicas e fenomenais. Com efeito, o fisicista não pode aceitar a suposição de Chalmers de que à luz do físicismo se poderia derivar a priori o conhecimento de fatos fenomenais do conhecimento de todas as verdades físicas e indexais. Ainda assim, o fisicista deveria poder fornecer uma explicação a posteriori para o fato de que propriedades fenomenais são propriedades físicas ou, pelo menos, sobrevêm às propriedades físicas.

A segunda tarefa que caberia à ECF seria agora selar a suposta lacuna ontológica entre as mesmas propriedades: ao fim e ao cabo não haveria distinção ontológica entre propriedades fenomenais e físicas. Eles seriam as mesmas propriedades, apenas consideradas de diferentes pontos de vista: sob conceitos físicos e sob conceitos fenomenais. Diante disso, o "quale vermelho" nada mais seria do que uma propriedade física (do cérebro ou representada pelo cérebro), apenas representada pelo conceito fenomenal recémadquirido.

A ECF enfrenta, contudo, sérias objeções. Meu foco aqui recairá apenas naquelas que são relevantes para o trabalho presente (cf. BALL, 2009; TYE, 2009). Conceitos gerais que empregamos introspectivamente para identificar o caráter fenomenal de nossas experiências são "deferenciais" no seguinte sentido: eles podem ser possuídos mesmo quando compreendidos apenas parcialmente. Como Tye formula: "talvez para se compreender plenamente um conceito fenomenal geral seja necessário realizar a experiência relevante. Ora, mas se tais conceitos são como os demais conceitos, alguém poderia possuí-los sem possuir um entendimento total" (2009, p. 63). A despeito do que sustenta Burge (2003, pp. 413-4), conceitos de cores também seriam "deferenciais" no sentido em que alguém os poderia possuir mesmo os compreendendo parcialmente, deixando-se então corrigir por um especialista em "deferência" à sua expertise relativa ao conceito. Ora, o mesmo pode ser dito de conceitos fenomenais (destinados à identificação dos qualia) 
Como o que nos permite então dizer que Mary encarcerada no seu quarto preto e branco possui o conceito relevante VERMELHO FENOMENAL para identificar o vermelho fenomenal por introspecção? A resposta me parece óbvia. Em seu confinamento, Mary é inteiramente capaz de falar e pensar tanto sobre a cor vermelha quanto sobre o fenomenal vermelho como qualquer pessoa que já tenha visto a cor vermelha. Por exemplo, mesmo confinada pode se perguntar se o verde fenomenal deixaria as pessoas mais calmas do que o verde fenomenal, ou ainda, se perguntar se o vermelho fenomenal deixaria as pessoas mais agitadas. O ponto principal é que o uso de Mary do conceito VERMELHO FENOMENAL satisfaz plenamente a restrição de generalidade de Evans (1982) para posse de conceitos. Sendo capaz de entreter o pensamento de que as maçãs maduras são VERMELHAS e que as experiências visuais das maçãs maduras possuem a propriedade VERMELHO FENOMENAL, ainda que aprisionada Mary também é capaz de empregar o mesmo conceito VERMELHO FENOMENAL como qualquer um.

Mas isso suscita uma questão adicional. Como os conceitos demonstrativos certamente não são "deferenciais" (no sentido assinalado), perguntase: quando confinada, Mary poderia possuir um conceito demonstrativo para identificar o caráter fenomenal de alguma experiência do vermelho? Segundo Tye, ela também pode possuir um conceito demonstrativo. Sob a suposição de que o caráter fenomenal da experiência é uma propriedade intrínseca do cérebro, Mary poderia possuir tal conceito demonstrativo de VERMELHO FENOMENAL apenas apontando através de um cerebroscópio para uma imagem do cérebro de alguém que estivesse realizando a experiência visual de algo vermelho. Isso significa não apenas que ela já possuía um conceito demonstrativo, mas também que tal conceito não é um conceito fenomenal no sentido relevante. A questão permanece de pé: o que explica o progresso epistêmico de May?

\section{Conteúdo não-conceitual}

Assumindo que VERMELHO FENOMENAL seja um conceito deferencial que Mary já possuiria em seu confinamento e que ela aprenda al- 
guma coisa ao contemplar um tomate maduro pela primeira vez, seu progresso epistêmico assume a forma de um aumento da sua expertise em relação ao conceito VERMELHO FENOMENAL. No caso famoso de Burge, o paciente que já possui o conceito de ARTRITE, mas aprende com seu médico que a artrite ocorre apenas nas articulações. No entanto, se Mary encarcerada já possui um conhecimento exaustivo da física de cores e visão de cores, como poderia aumentar sua expertise em relação ao conceito VERMELHO FENOMENAL? Ora, única capacidade de que Mary, quando confinada, poderia carecer é a capacidade de discriminar a cor vermelha das demais cores e de um pano de fundo. Diante disso, é essa capacidade discriminatória que deve poder explicar tanto o incremento da expertise de Mary quanto ao conceito VERMELHO FENOMENAL, quanto, pelo menos em parte, o seu progresso epistêmico ao contemplar um tomate maduro pela primeira vez.

A questão que se coloca agora é sobre a natureza dessa representação visual recém-adquirida pela contemplação da cor do tomate maduro. Segundo Dretske, essa representação seria nem proposicional nem conceitual (cf. DRETSKE, 1969; SCHELLENBERG, 2018). Ao ser libertada, olhando para a cor vermelha de um tomate maduro, Mary começa a representar a cor vermelha pela primeira vez de maneira não-conceitual. De fato, essa parece ser a peça que faltava em todo o quebra-cabeça do argumento do conhecimento. Por mais engenhosa que seja Mary, possuindo conhecimento exaustivo de cores e visão de cores, seu domínio do conceito VERMELHO FENOMENAL não é completo. Com efeito, no âmbito estritamente descritivo, não há nada que Mary desconheça sobre a experiência visual da cor vermelha. Não obstante, Mary carece de algo, a saber da representação visual não-conceitual da cor vermelha (já que ela nunca havia visto o vermelho antes). Se isso estiver certo, do que Mary carece, quando aprisionada, não é de um novo conceito fenomenal especial (que ela supostamente não poderia possuir antes), mas antes de uma nova representação não-conceitual da cor vermelha. Mas agora o leitor irá me indagar: mas por que tal conteúdo não é conceitual?

Antes de mais nada, deixem-me lembrar de algumas das principais características da noção de conteúdo representacional não-conceitual. Para 
início de conversa, um conteúdo representacional não é conceitual quando a sua especificação canônica não exige por parte do sujeito que o possui quaisquer conceitos envolvidos nesta especificação. Ora, se Mary quando aprisionada possui conhecimento exaustivo da física da visão do vermelho, a sua representação visual recém-adquirida da cor vermelha é independente de seu conceito de VERMELHO FENOMENAL e de quaisquer conceitos que ela possa possuir. Diante disso, a suposição razoável é a de que a representação recém-adquirida não é conceitual.

Segundo, estados mentais de natureza não-conceitual veiculam informação codificada na chamada forma analógica; em oposição aos estados mentais de natureza conceitual como atitudes proposicionais que transmitem informação codificada na forma digital. A distinção entre umas e outras foi claramente formulada por Dretske (1981) no seguintes termos. Tome um fato qualquer, digamos o fato ou estado de coisas em que algum objeto $S$ tem a propriedade de $F$. Uma representação que veicula a informação de que $S$ é $F$ está codificada no formato digital se não veicular informações adicionais "aninhadas" (nested) sobre $S$ além de $F$. Em contrapartida, sempre que uma representação veicula a informação de que $S$ é $F$ codificada na forma analógica, sempre veicula informações adicionais "aninhadas" (nested) sobre S, grosso modo que S é G, que S é H, etc. (Cf. DRETSKE, 1981, capítulo 6$)$.

Terceiro, o conteúdo não-conceitual é sempre mais refinado do que o conteúdo conceitual. Com efeito, sou capaz de discriminar um número indefinidamente maior de cores, formas, odores, tons etc. do que realmente sou capaz de conceituar. Por exemplo, posso ser capaz de discriminar entre dois tons muito semelhantes de vermelho, digamos o vermelho1281 do vermelho1282. No entanto, por maior que seja a minha acuidade visual, provavelmente não serei capaz de conceituar os tons em questão simplesmente porque não sou capaz de reter na memória a discriminação visual que sou capaz de realizar.

Quarto, conteúdos de natureza não-conceitual são essencialmente involuntários e independentes de qualquer julgamento ou de qualquer outro tipo de atitude proposicional. Assim, um estado mental apresenta o mundo 
não-conceitualmente de uma forma ou de outra (condições de veridicalidade), essa representação é independente da vontade ou julgamento da pessoa.

A quinta característica é uma consequência direta da terceira. Como meus estados não-conceituais representam o mundo independentemente de minha vontade e meu julgamento, esse conteúdo não está sob o controle de minhas atitudes proposicionais (a chamada tese de "penetração cognitiva da percepção"). Segundo Pylyshyn (1999), um sistema perceptivo é cognitivamente penetrável se "a função que ele calcula é sensível, de uma maneira semanticamente coerente, aos objetivos e crenças do organismo, ou seja, pode ser alterada de uma maneira que tenha alguma relação lógica. ao que a pessoa sabe" (1999, p. 343). Certamente, a posição de Pylyshyn está longe de ser consensual. Ainda assim, parece-me razoável endossar a visão de Pylyshyn de que "o sistema de visão precoce faz seu trabalho sem a intervenção de conhecimentos, crenças ou expectativas, mesmo quando o uso desse conhecimento o impediria de cometer erros" (1999, p. 414).

Agora, quero consubstanciar minha afirmação considerando o famoso caso de Mariana sugerido por Nida-Rümelin (1996). Como a Mary original de Jackson, Mariana é mantida em cativeiro em uma sala em preto e branco. Ao contrário de Mary, no entanto, quando Mariana sai da sala em preto-e-branco, ela é levada a um vestíbulo colorido, no qual existem várias manchas de cores diferentes nas paredes. A essa altura, ela realizará experiências que nunca realizou antes: vermelho, amarelo, azul e assim por diante. No entanto, como ela não vê maçãs, tomates ou hidrantes, Mariana não tem a menor ideia de qual cor está vendo é quando contempla uma mancha vermelha na parede da sala. Como ela já possui os conceitos VERMELHO e VERMELHO FENOMENAL, mas é incapaz de reconhecer como vermelho o que está contemplando ou como vermelho fenomenal o caráter fenomenal da experiência da cor vermelha que está realizando, a suposição razoável é que Mariana deve estar representando tanto a cor vermelha quanto o caráter fenomenal da sua nova experiência de vermelho de maneira não-conceitual. Mas por que isso é assim?

Antes de mais nada, no vestíbulo colorido, o aparato conceitual de Mariana sobre cores e visão de cores não serve para nada. Reiterando, ela não tem a mínima ideia de que o que ela está contemplando uma mancha 
vermelha ou de que está realizando uma experiência cujo caráter fenomenal seja o vermelho fenomenal. Em segundo lugar, no quarto colorido, não há o que na ciência cognitiva se usa chamar de "processamento cross-modal" (O processamento cross-modal ocorre quando dois sistemas sensoriais interagem. Por exemplo, quando as informações processadas em uma modalidade, como a audição, podem afetar as informações processadas em outra modalidade, a visão ou a experiência de uma modalidade, a visão, pode afetar a experiência. teve em outra modalidade, digamos, tocar.). Ora, as manchas vermelhas na parede do quarto não têm cheiro, textura, sabor, etc. Ademais, o reconhecimento conceitual da cor vermelha e do vermelho fenomenal depende não apenas do conceito VEMELHO e do conceito VERMELHO FENOMENAL, mas também do conhecimento de que o que ela está vendo é um tomate maduro (e do seu conhecimento de background que tomates maduros são vermelhos). Mas vamos analisar o caso de Mariana à luz das caraterísticas apresentadas anteriormente uma a uma.

Primeiro, conteúdos não-conceituais são aqueles cuja especificação canônica envolve conceitos que o sujeito possuidor dos respectivos estados mentais não necessariamente possui. Ora, quando especificamos como vermelho o conteúdo da representação visual de Mariana e como vermelho fenomenal o caráter fenomenal da nova experiência de vermelho que ela realiza, ela própria é incapaz de reconhecer como vermelho e como vermelho fenomenal o que está representando. Assim, pela própria definição geral do que venha a ser um conteúdo não-conceitual, Mariana representa visualmente a cor vermelha (e introspectivamente o vermelho fenomenal) independentemente dos seus antigos conceitos de VERMELHO e de VERMELHO FENOMENAL. As coisas mudam quando ela é finalmente libertada do vestíbulo colorido ela vem a contemplar um tomate maduro em um espaço aberto à luz do dia.

Em segundo lugar, quando confinada, Mariana representa tanto a cor vermelha quanto o vermelho fenomenal da sua nova experiência por meio de estados mentais que veiculam informações no formato digital e não no formato analógico. Por um lado, sempre que ela pensa em vermelho ou em vermelho fenomenal, seu estado mental veicula informações sobre vermelho e sobre o vermelho fenomenal, retrospectivamente sem veicular quaisquer 
informações adicionais. Por outro lado, em seu quarto colorido, ao contemplar a mancha vermelha na parede, seu estado mental que veicula informações sobre a cor vermelha, veicula informações adicionais sobre, por exemplo, a forma da mancha vermelha na parede, sobre as condições de iluminação do ambiente, sobre a distância da mancha, etc. Portanto, a representação visual recém-adquirida por Mariana não pode ser de natureza conceitual.

Quarto, a despeito da capacidade conceitual refinada de Mariana para pensar em vários tons de vermelho, ao contemplar vários tons de vermelho na parede do vestíbulo colorido, ela está representando tons bastante específicos de vermelho, digamos algo como o vermelho 2345, 2346, 2347, etc. Ora, isso é algo que ultrapassa a capacidade conceitual de Mary. Ademais, quando Mariana contempla fixamente para uma mancha vermelha na parede de seu vestíbulo em tecnicolor, digamos vermelho 12354, ela provavelmente nunca será capaz de conceituar esse tom específico de vermelho, pela simples razão de que nunca será capaz de memorizar esse tom específico. Mais uma vez, em face de todos os critérios listados acima, a suposição razoável é que as representações (visual e introspectiva) recém-adquiridas por Mariana tanto do vermelho quanto do vermelho fenomenal sejam de natureza essencialmente não-conceituais.

\section{Arquivos mentais}

Ora, mesmo que essa representação não-conceitual do vermelho fenomenal seja necessária, ela certamente não é suficiente para a explicação do progresso epistêmico de Mary. Algo a mais está faltando, a saber, o conceito VERMELHO FENOMENAL. Primeiro, a grande maioria de nossas representações não-conceituais não é sequer processada. Eles são simplesmente descartadas. Elas, por um lado, carecem de relevância cognitiva e, por outro, sendo irrelevantes acabam sobrecarregando o sistema cognitivo. Segundo e, mais importante, elas só podem contribuir para a cognição quando adequadamente conceituadas. Na semântica informacional de Dretske, as informações codificadas analogicamente devem ser digitalizadas, fazendose "abstração" de todos os detalhes irrelevantes. 
Retomando as críticas de Tye e Ball, assumo que não haja conceitos fenomenais no sentido especial exigido pela ECS, ou seja, conceitos que identifiquem o caráter fenomenal da experiência por via introspectiva, mas que só poderiam ser adquiridos pela experiência relevante. Mesmo assim, acredito que a vasta literatura sobre a ECS pode nos fornecer uma pista sobre o entendimento adequado de como conteúdos não-conceituais podem conceituados de modo fornecer uma explicação para o progresso de Mary.

Deixem-me começar por reconsiderar brevemente a natureza dos conceitos fenomenais. O locus classicus para o ECS é o artigo de Loar "Phenomenal States", no qual ele afirma que conceitos fenomenais são conceitos de reconhecimento (cf. LOAR, 1990; 1997). Um conceito de reconhecimento, diferentemente de um conceito teórico, é empregado diretamente com base no conhecimento perceptivo de suas instâncias, ou seja, quando reconhecemos um objeto "como sendo um deles", sem depender de conhecimento teórico ou de conhecimento prévio. Carruthers (2004), Tye $(1995 ; 2000)$ e Levine (2006) endossaram contas semelhantes no passado recente.

Por outro lado, de acordo com outra concepção, conceitos fenomenais são indexicais por natureza (cf. HORGAN, 198; ISMAEL, 1999; PERRY, 2001; e O’DEA, 2002). São conceitos do tipo demonstrativo que identificam os estados mentais mediante um modo demonstrativo de apresentação. A sugestão aqui é que a lacuna epistêmica entre propriedades físicas e fenomenais seria de algum modo semelhante às lacunas conhecidas entre conceitos objetivos e os conceitos fenomenais. Os conceitos fenomenais seriam como conceitos demonstrativos "flexíveis" internos que identificam o caráter fenomenal mediante introspecção da mesma maneira que demonstrativos identifica objetos no espaço. Um terceiro grupo de filósofos, que cabe mencionar aqui, define os conceitos fenomenais por seu papel conceitual. Conceitos fenomenais e físicos estão associados a faculdades e modos de raciocínio distintos (cf. NAGEL, 1974; STURGEON, 1994; HILL, 1997; e REY, 1998).

No entanto, de acordo com a visão mais popular, conceitos fenomenais são conceitos de "citações", ou seja, são conceitos que de alguma forma contêm os próprios estados ou imagens fenomenais aos quais se referem introspectivamente (cf. PAPINEAU, 2006; e BLOCK, 2006). Nesse particular, 
uma sugestão interessante foi proposta por Papineau (2002; 2007). Conceitos fenomenais são como modelos (templates) sensoriais cuja função é acumular informações sobre os referentes relevantes, armazenando cópias da experiência. Conceitos fenomenais usariam as cópias da experiência armazenadas no arquivo para fazer menção à própria experiência. No entanto, tal processo nem é simples nem imediato. Os arquivos mentais podem apenas abrigar cópias digitalizadas ou réplicas da experiência em questão. Todas as informações não relevantes são descartadas. Por exemplo, se Mary contempla um tom bastante específico de vermelho, digamos o vermelho 124568, a sua memória retém apenas algo aproximadamente como vermelho12.

Assumindo então que não existam conceitos fenomenais (no sentido especial que a ECS exige), a suposição razoável aqui é a de que Mary simplesmente reutiliza seu antigo conceito físico VERMELHO FENOMENAL para identificar agora introspectivamente o vermelho fenomenal de sua nova experiência visual da cor do tomate maduro. Em outras palavras, pelo menos no caso das cores (em contraste com o caso das sensações corporais), reutilizamos o mesmo conceito físico VERMELHO FENOMENAL para conceituar (agora introspectivamente) a experiência relevante da cor vermelha.

Nestes termos alcanço a minha segunda tese fundamental. Supondo que os conceitos sejam como arquivos mentais, depois que Mary realiza a experiência da cor vermelha de um tomate maduro pela primeira vez, uma imagem mental é devidamente digitalizada e passa a ser armazenada no seu antigo conceito VERMELHO FENOMENAL. Esse não é um conceito fenomenal no sentido especial, bastante específico, exigido pela ECP, mas antes um conceito físico enriquecido por imagens fenomenais oriundas de conteúdos de natureza essencialmente não-conceitual. Podemos chamá-lo de conceitos "fenomenalmente enriquecidos". Ora, é somente após a incorporação da imagem mental digitalizada do vermelho em seu antigo arquivo VERMELHO FENOMENAL que Mary passa a saber o que é. enfim, realizar a experiência de vermelho. 


\section{Referências}

ALTER, Torin. Social externalism and the knowledge argument. Mind, v. 122, n. 486, p. 481-496, 2013.

BACH, Kent. Thought and reference. 1987.

BLOCK, Ned. Max Black's objection to mind-body identity. Oxford studies in metaphysics, v. 3, p. 3-78, 2006.

BLOCK, Ned; STALNAKER, Robert. Conceptual analysis, dualism, and the explanatory gap. The Philosophical Review, v. 108, n. 1, p. 1-46, 1999.

BURGE, Tyler. Individualism and the Mental. Midwest studies in philosophy, v. 4, n. 1, p. 73-121, 1979.

BURGE, Tyler; HAHN, Martin; RAMBERG, Bjørn T. (Ed.). Reflections and replies: Essays on the philosophy of Tyler Burge. MIT press, 2003.

CARRUTHERS, Peter. Phenomenal concepts and higher-order experiences. Philosophy and Phenomenological Research, v. 68, n. 2, p. 316-336, 2004.

CHALMERS, David J. The character of consciousness. Oxford: Oxford University Press, 2010.

DRETSKE, Fred I. Seeing and knowing. Chicago: University of Chicago Press. 1969.

DRETSKE, Fred I. Naturalizing the mind. Cambridge, MA: MIT Press, 1997.

DRETSKE, Fred. Knowledge and the Flow of Information. Cambridge, MA: MIT Press, 1981.

EVANS, Gareth. The Varieties of Reference. Oxford: Oxford University Press, 1982.

HILL, Christopher S. Imaginability, conceivability, possibility and the mindbody problem. Philosophical Studies: An International Journal for Philosophy in the Analytic Tradition, v. 87, n. 1, p. 61-85, 1997.

HORGAN, Terence. Jackson on physical information and qualia. The Philosophical Quarterly (1950-), v. 34, n. 135, p. 147-152, 1984.

ISMAEL, Jenann. Science and the phenomenal. Philosophy of Science, v. 66, n. 3, p. 351-369, 1999.

JACKSON, Frank. Epiphenomenal qualia. The Philosophical Quarterly (1950-), v. 32, n. 127, p. 127-136, 1982. 
LEVINE, Joseph. eight Phenomenal Concepts and the Materialist Constraint. Phenomenal concepts and phenomenal knowledge: New essays on consciousness and physicalism, p. 145, 2006.

LEVINE, Joseph. Materialism and qualia: The explanatory gap. Pacific philosophical quarterly, v. 64, n. 4, p. 354-361, 1983.

LEVINE, Joseph. Purple haze: The puzzle of consciousness. Oxford: Oxford University Press, 2001.

LOAR, Brian. Phenomenal States. Philosophical Perspectives. v. 4, p. 81108. 1990.

LUPYAN, Gary. Cognitive penetrability of perception in the age of prediction: Predictive systems are penetrable systems. Review of philosophy and psychology, v. 6, n. 4, p. 547-569, 2015.

NAGEL, Thomas. What is it like to be a bat?. The philosophical review, v. 83, n. 4, p. 435-450, 1974.

NIDA-RÜMELIN, Martine; O CONAILL, Donnchadh. Qualia: The knowledge argument. 2002.

O'DEA, John. The indexical nature of sensory concepts. Philosophical Papers, v. 31, n. 2, p. 169-181, 2002.

PAPINEAU, D. Phenomenal and perceptual concepts and the materialist constraint. In: ALTER, T.; S. WALTER (Eds.). Phenomenal concepts and phenomenal knowledge: New essays on consciousness and physicalism, p. 111-144, 2006.

PAPINEAU, David. Thinking about consciousness. Oxford: Clarendon Press, 2002.

PERRY, John. Knowledge, Possibility and Consciousness: The 1999 Jean Nicod Lectures. Cambridge, MA: MIT Press, 2001.

PYLYSHYN, Zenon. Is vision continuous with cognition?: The case for cognitive impenetrability of visual perception. Behavioral and brain sciences, v. 22, n. 3, p. 341-365, 1999.

REY, Georges. A narrow representationalist account of qualitative experience. Philosophical perspectives, v. 12, p. 435-457, 1998.

STOLJAR, Daniel. Physicalism and phenomenal concepts. Mind \& language, v. 20, n. 5, p. 469-494, 2005.

STURGEON, Scott. The epistemic view of subjectivity. The Journal of Philosophy, v. 91, n. 5, p. 221-235, 1994. 
Perspectiva Filosófica, vol. 46, n. 1, 2019

TYE, Michael. A theory of phenomenal concepts. Royal Institute of Philosophy Supplements, v. 53, p. 91-105, 2003.

TYE, Michael. Consciousness Revisited: Materialism without Phenomenal Concepts. Cambridge, MA: MIT Press. 2009.

TYE, Michael. Knowing what it is like: The ability hypothesis and the knowledge argument. in Tye, M., Consciousness, Color, and Content, Cambridge, MA: MIT Press, 2000.

TYE, Michael. Ten problems of consciousness: A representational theory of the phenomenal mind. Cambridge, MA: MIT Press, 1995. 